\title{
Skin Atrophy
}

National Cancer Institute

\section{Source}

National Cancer Institute. Skin Atrophy. NCI Thesaurus. Code C35163.

The degeneration and thinning of the epidermis and dermis. It is usually a manifestation of aging. 